\title{
(RE)SIGNIFICANDO O DISCURSO DOS DIREITOS HUMANOS: UM DIÁLOGO A PARTIR DA EDUCAÇÃO EM E PARA OS DIREITOS HUMANOS
}

\author{
Renato Duro Dias ${ }^{1}$ \\ Amanda Netto Brum ${ }^{2}$
}

\begin{abstract}
Resumo
Este estudo propõe refletir acerca da moderna concepção do discurso dos Direitos Humanos. Para tal, realizou-se uma revisão da literatura, a partir da técnica de pesquisa da documentação indireta, de cunho narrativo ancorada nos estudos culturais e pós-modernos de matriz crítica. Interroga-se, inicialmente, quais vidas são enquadradas como humanas e, portanto, sujeitas à humanidade e passíveis de Direitos Humanos. Já em um segundo momento, realiza-se uma reflexão acerca da (re)significação discursiva sobre estes direitos. Pretende-se, desse modo, evidenciar a necessária oposição à episteme tradicional do conhecimento, em especial quanto do discurso dos Direitos Humanos, pois, o regime de verdades, ao reafirmar a produção dos saberes por meio das relações de poder, engendra esse a construção discursiva hegemônica, bem como encerra o seu reconhecimento a atual política discursiva. Entende-se, neste contexto, que a educação em e para os direitos humanos constitui-se em potente espaço de transformação destes contextos, pois pode não apenas potencializar a produção de um conhecimento emancipado e dar voz a quem foi silenciado, mas, em especial, pode reconfigurar corpos e vidas precárias.
\end{abstract}

Palavras-chave: Direitos Humanos; Reconhecimento; Condição Humana; Discurso Hegemônico; Educação em Direitos Humanos.

\section{INTRODUÇÃO}

Contemporaneamente, as problematizações acerca dos Direitos Humanos tornaram-se centrais em distintas áreas do saber. No entanto, há diversos questionamentos possíveis, especialmente acerca do reconhecimento desses direitos tanto enquanto premissa de humanidade, isto é, da condição humana, quanto do reconhecimento dos espaços tradicionais hegemônicos - dos quais gozam cotidiana e historicamente a voz do pensamento branco, masculino (ESCRIVÃO FILHO, SOUSAJÚNIOR, 2016) e heterossexual.

Inseridos, neste contexto, muitos têm sido os debates acerca dos Direitos Humanos que têm concedido

\footnotetext{
${ }^{1}$ Doutor em Educação pela Universidade Federal de Pelotas - UFPEL. Professor da Graduação de Direito e do Mestrado em Direito e Justiça Social da Universidade Federal do Rio Grande - FURG. E-mail: renatodurodias@gmail.com

${ }^{2}$ Mestre em Direito e Justiça Social - FURG. E-mail: amandanettobrum@gmail.com
} 
visibilidade a distintos grupos de sujeitos ou de sujeitos que vivenciam situação de precariedade, de abjeção, ${ }^{3}$ de subalternidade e de vulnerabilidade - como os suscitados por meio do "fenômeno" da expansão política da justiça.

Nesse contexto, de acordo com Butler (2015a), a precariedade se traduz numa subordinação das condições políticas do sujeito-humano, em que uma parcela (ou parte de um grupo humano) é condenada ao sofrimento, à barbárie, há uma subsunção ao espaço do silêncio, da opacidade, do vazio, das precárias redes sociais e econômicas do estado. Deste modo, esses grupos (mulheres, negros, população LGBT, ciganos e migrantes) estão mais expostos à violência, ao risco e à vulnerabilidade, não social, mas, sobretudo, política. São corpos que importam menos, vidas precárias que se submetem, diariamente, às injustiças e às indignidades.

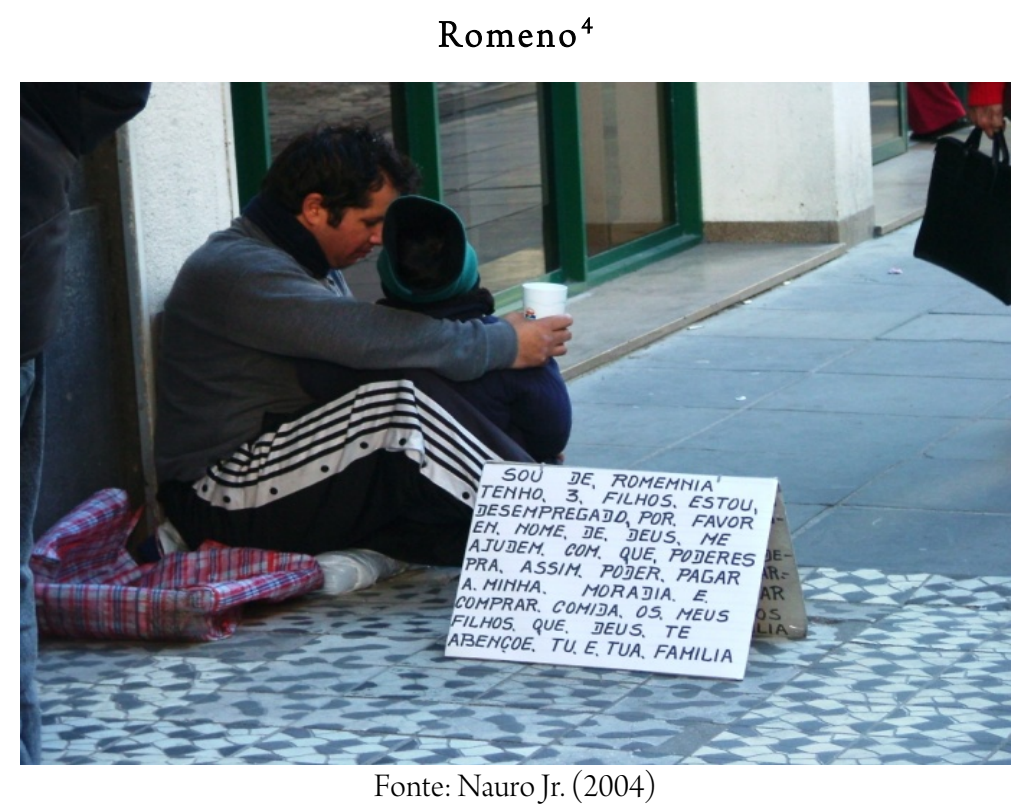

No entanto, a ordem social, ainda (re)produz desigualdades de toda a ordem (BERTÚLIO, 2013) e, sendo assim, direciona diversas formas cotidianas de discriminação e opressões que incluem interdições, ${ }^{5}$ silenciamentos, desqualificações e, em muitas situações, não-reconhecimento de direitos a determinados sujeitos, grupos ou classes (BRUM, DIAS, 2015).

Assim, ainda hoje, são inúmeras as formas de não-reconhecimento direcionadas aos sujeitos não

\footnotetext{
${ }^{3}$ De acordo com Butler (2015b) os corpos abjetos (que vivem na zona da abjeção) são os que não encontram legitimidade na ordem social por não se enquadrarem nos ideais hegemônicos, por exemplo, de gêneros, das sexualidades e de raça.

${ }^{4}$ As imagens utilizadas neste estudo fazem parte do acervo fotográfico cedido pelo fotógrafo Nauro Jr.. Estas fotografias foram, parcialmente, utilizadas em Relações de Poder e Controle no Currículo do Curso de Direito (2014) de Renato Duro Dias, obra editada pela Lumen Juris (no prelo).

${ }^{5}$ A terminologia interdição, nesta análise, é utiliziada de acordo com o poreceituado por Foucault (2014). Para o autor, o sujeito é condenado, classificado, obrigado a desempenhar tarefas e destinado a um certo modo de viver em função do discurso hegemônico dito verdadeiro. $\mathrm{O}$ processo de sujeição ou os processos contínuos e ininterruptos sujeitam, diregem, regem comportamentos e interditam vidas, isto é, exculem vidas dos discursos hegemônicos.
} 
padronizados pelo qualificativo humano ${ }^{6}$ (ESCRIVÃO FILHO, SOUSA JÚNIOR, 2016), seja em virtude da sua raça, da sua identidade de gêneros ${ }^{7}$ ou/e sexual, da sua sexualidades ${ }^{8}$ ou em relação a quaisquer características físicas ou comportamentais que escapam ao padrão de normalidade naturalizado pelo marco discursivo hegemônico (BUTLER, 2012). Nesse panorama, cabe ressaltar que, Butler, com base em Foucault, enfatiza que o discurso constrói o sujeito, o que suscita um processo histórico que expressa uma luta pelo poder, no que se refere à prerrogativa de dizer o que está em consonância com o padrão epistemológico. Como resultado, surge um discurso hegemônica que regula a construção das vidas humanas (BUNCHAFT, 2016, p. 348-349).

Impõe-se, frente a esta realidade, urgente, questionar novos paradigmas para a ciência moderna, em especial acerca da concepção do discurso dos Direitos Humanos, capazes de desconstruir e (re)significar as categorias construídas a partir do marco normativo hegemônico.

Nesse contexto, propõe-se, com este estudo, refletir acerca da concepção moderna do discurso dos Direitos Humanos. Para tanto, realizou-se uma revisão da literatura, a partir da técnica de pesquisa da documentação indireta, de cunho narrativo ancorada nos estudos culturais e pós-modernos de matriz crítica, em especial das contribuições de Foucault $(2010,2014)$ e de Butler (2012, 2015a, 2015b).

Dessa forma, em um primeiro momento, problematizou-se o consenso da condição humana, ou seja, interrogou-se quais vidas são enquadradas como humanas e, portanto, sujeitas à humanidade e passíveis de Direitos Humanos, já em um segundo momento, realizou-se uma reflexão acerca da (re)significação discursiva sobre estes direitos e, por fim, propor-se a educação em e para os direitos humanos como um espaço de transformação dos contextos que interditam, silenciam e desqualificam os sujeitos.

Este estudo pretende, portanto, evidenciar a necessária oposição à episteme atual do conhecimento da ciência moderna, em especial quanto ao discurso dos Direitos Humanos, pois, o regime de verdades, ao reafirmar a produção dos saberes por meio das relações de poder, engendra esse a construção discursiva hegemônica, bem como encerra o seu reconhecimento a atual política discursiva.

\section{VIDAS QUE IMPORTAM PARA A CONCEPÇÃO DOS DIREITOS HUMANOS}

No contexto ocidental, contemporaneamente, as problematizações acerca dos Direitos Humanos

\footnotetext{
${ }^{6} \mathrm{O}$ qualitativo humano funciona como um redutor social e cultural que reconhece o humano entre as vidas e apreende determinada vida como humana. Trata-se, portanto, de enquadrar determinadas vidas como humanas a partir do enquadramento epistemológico hegemônico, isto é, masculino, branco e heteressoxual (BUTLER, 2015a).

7 O termo "gênero" é grafado, neste escrito, dentro dos limites que a própria linguagem impõe, como "gêneros" (grifo do autor) como forma de significar e compreender a categorização de gêneros para além do binarismo determinado pelo padrão discursivo heteronormativo.

${ }^{8}$ Utiliza-se o termo sexualidades, pois em conformidade com Dias e Alves $(201 \neg 2$, p. 5$)$ a terminologia sexualidade deve ser grafada como sexualidades por ser uma "terminologia cunhada nas duas últimas décadas com o sentido de pluralidade na diversidade sexual" (grifo dos autores).
} 
constituem núcleo de importantes debates e embates teórico-práticos. Nesse contexto, faz-se fundamental repensar quais vidas são reconhecidas como humanas (BUTLER, 2015a), isto é, quais corpos gozarão da condição humana e, portanto, serão reconhecidas como sujeitos passíveis de Direitos Humanos.

A luta por reconhecimento para além de se referir às conquistas de direitos aos sujeitos questiona, em especial - ao perturbar a construção dos espaços de hegemonia, de hierarquia e de privilégios, dentre outros campos de poder, estabelecidos na ordem social - a episteme atual do conhecimento.

Isso porque se entende que ao ser problematizado o reconhecimento da condição humana aos sujeitos o referencial de humanidade - branco, masculino e heterossexual - é provocado e interrogado e, com isso, também, a concepção de "sujeito de humanidade" é questionada.

Logo, a partir dessa perspectiva, as fronteiras de inteligibilidade social e, sobretudo, de humanidade passam a ser descontruídas, desestabilizando, com isso, as barreiras de reconhecimento impostas pelo padrão epistemológico atual; este que enquadra a condição humana a determinadas formas estabelecidas pela lógica normativa hegemônica, pois é a partir da luta pelo direito de ser reconhecido que se percebe que o status de sujeito ata e conduz à vulnerabilidade, à precariedade e à constante exposição do "outro" (TONELI, AMARAL, 2013).

Ocorre que, os termos que possibilitam o reconhecimento da condição humana são dados, no contexto social, pelo regime de verdades (FOUCAULT, 2010). Isto é, o regime de verdades determina o que constituirá e não constituirá como verdadeiro, ao mesmo tempo que produz, a partir da norma, verdades que transmitem as formas hegemônicas (sociais, culturais, econômicas, políticas e de linguagem) e que, por sua vez, reafirmam os saberes que instituem e disciplinam os corpos a condição de sujeito humano (FOUCAULT, 2014).

Quer dizer que:

estamos submetidos à produção da verdade também no sentido em que ela é lei e produz o discurso verdadeiro que decide, transmite e reproduz, ao menos em parte, efeitos de poder. Afinal, somos julgados, condenados, classificados, obrigado a desempenhar tarefas e destinos a um certo modo de viver ou morrer em função dos discursos verdadeiros que trazem consigo efeitos específicos de poder (FOUCAULT, 2014, p. 279).

Sendo assim, os termos do reconhecimento são apresentados pelo discurso, de modo que este qualifica o humano e determina o não-humano (inumano) - ou o humano que apaga o humano como uma alteridade conhecida (BUTLER, 2015a).

Cabe mencionar que a política discursiva, forma, articula e (re)produz, na ordem social, os discursos ditos verdadeiros e precariza os demais (FOUCAULT, 2010), assim, as relações de poder reduzem a política discursiva a lógica binarizante. Desse modo, o discurso funciona como um mecanismo de controle e qualificação dos sujeitos às normas hegemônicas (FOUCAULT, 2014).

Mas além disso, a capacidade epistemológica de precarizar e subalternizar determinados sujeitos e, 
portanto, vidas depende da modelagem e do enquadramento social e cultural estabelecido pela construção discursiva hegemônica que pressupõe a condição masculina, branca e heterossexual como único sujeito de reconhecimento de humanidade (ESCRIVÃO FILHO, SOUSA JÚNIOR, 2016).

Nesse sentido, "a produção de significações que se traduz a partir do discurso hegemônico, faz gerar uma inevitável e desastrosa sequência de novos discursos e práticas que acabam enjaulando/aprisionando o corpo a uma única e admissível forma” (DIAS, 2015, p. 475) de vida.

De fato, a valorização e a qualificação, do corpo ao qualitativo da condição humana baseado em algumas características como a raça, as identidades de gêneros e/ou sexual performatizadas e as sexualidades vivenciadas e experimentadas pelos sujeitos, ainda, é fortemente arraigada no imaginário social e vem sustentando desigualdades, discriminações, abjeções e não-reconhecimentos de direitos.

Assim, por exemplo, caso o corpo não performatize a condição de vida entabulada no discurso compreendido como verdadeiro esse sequer será considerado sujeito, ou melhor, existirá algo que será considerado vivo, mas que, por transgredir a norma hegemônica, esta vida não será reconhecida como humana e, por isso, não será reconhecível como sujeito de Direitos Humanos (BULTER, 2015a).

No entanto, "ao analisar o cenário social brasileiro com mais de uma centena de entidades organizadas em torno da assessoria jurídica e advocacia popular em diversos temas de direitos humanos" (ESCRIVÃO FILHO, SOUSA JÚNIOR, 2016, p. 178) e aliado a uma produção legislativo, mesmo que discreta, que busca promover a efetivação de direitos humanos a diversos sujeitos - como a Lei 11.340 de 7 de agosto de 2006 torna-se, atualmente, fundamental observar que há conquistas positivas na promoção dos direitos humanos a determinados sujeitos historicamente precarizados e, portanto, verdadeiros avanços.

Do ponto de vista da efetivação da promoção do protagonismo democrático desses direitos, existem, entretanto, ainda, muitos questionamentos e problematizações possíveis, como o proposto neste escrito, pois demonstra-se primordial transgredir e (re)significar os limites impostos pelo discurso hegemônico no que atine a construção de sujeitos politicamente empoderados.

De fato, há, na ordem social, "um redutor cultural que localiza num grau de identidade em que o 'outro' não está propriamente reconhecido" (ESCRIVÃO FILHO, SOUSA JÚNIOR, 2016) às normas hegemônicas, assim, o "outro" ao constituírem e construírem fora do regime discursivo de verdades (FOUCAULT, 2010) é condicionado ao conteúdo impositivo da humanidade normalizadora (BUTLER, 2012).

Isso ocorre em consequência da lógica discursiva que ao transmitir a lógica binarizante (FOUCAULT 2010) - estabelecendo fronteiras ao corpo -, serve ao propósito de instaurar e naturalizar certas vidas aos limites, posturas e formas apropriadas que definem e estabelecem o que constitui a condição humana (BUTLER, 2012).

A rigor, o regime de verdades, como estabelecido acima, no contexto social, delimita quais sujeitos serão 
qualificados como humanos e determina os que não serão (BUTLER, 2015a). Todavia, ao ser reconhecido o corpo inumano - aquele que não se conforma a figura naturalizada do corpo humano, ou seja, não há consenso sobre a sua condição de humana -, está-se não somente possibilitando subverter a norma ao ser encontrando espaços de singularidade que possibilitam desfazer as formas de vidas inumanas como, em especial, transgredir a violência normativa do conceito de humanidade (BUTLER, 2015b).

Frente a isso, demonstra-se fundamental refletir quais vidas (BUTLER, 2015a) são enquadradas como humana e, portanto, sujeitas à humanidade e passíveis de direitos, pois:

se certas vidas não são qualificadas como vidas ou se, desde o começo, não são qualificadas vidas como vidas de acordo com certos enquadramentos epistemológicos, então essas vidas nunca serão vividas nem perdidas no sentido pleno dessas palavras (BUTLER, p.13, 2015a).

Ocorre que, o ato do reconhecimento da humanidade às vidas de determinados sujeitos é constituído a partir das estruturas normativa, jurídica, política e de linguagem (BUTLER, 2015a) - estabelecido por meio das relações de poder -, assim, a condição de humanidade "é produzida mediante normas, que quando repetidas, produzem e deslocam os termos por meio dos quais os sujeitos são reconhecidos como humanos" (BUTLER, p. $17,2015 a)$.

Isso se dá porque as relações de poder utilizando-se do discurso, formam e fabricam o sujeito, assim, este é um dos maiores e importantes efeitos daquele (FOUCAULT, 2014). O discurso não apenas constrói aquilo que nomeia, mas, sobretudo, produz os sujeitos (FOUCAULT, 2014) e determina quais corpos serão qualificados como inumamos, ou seja, quais corpos não serão reconhecíveis como sujeitos e, portanto, nunca terão reconhecido a sua humanidade (BUTLER, 2015a).

Nesse sentido, oportuna a reflexão proposta por Escrivão Filho e Sousa Júnior (2016) quando questionam quais graus de consciência e de consenso nos colocamos nos dias atuais quando do ato de reconhecimento de humanidade e, consequentemente, dos Direitos Humanos aos sujeitos, fundamentalmente "nas situações de intensa luta por reconhecimento que, a partir da raiz da nossa formação colonial, patriarcal e racial, anima o processo emancipatório de segmentos subalternizados, excluídos" (ESCRIVÃO FILHO, SOUSA JÚNIOR, p. 20, 2016), precarizados e vulnerabilizados (BUTLER, 2015), "cuja síntese configura como uma dramática experiência de humanização" (ESCRIVÃO FILHO, SOUSA JÚNIOR, p. 20, 2016).

O que significa dizer, que as normas que delimitam e qualificam o corpo como humano dependem fundamentalmente das relações sociais e políticas em que o sujeito vive, de como este é considerado e tratado e, de como essa consideração e esse tratamento, possibilitam o reconhecimento de humanidade dessa vida (BUTLER, 2015a).

Nota-se que, o corpo é "mergulhado num campo político; as relações de poder, por meio da biopolítica, operam sobre ele uma influência imediata, elas investem contra ele e o reprimem" (COURTINE, 2013, p. 16). 
Padrões de normalidade — do humano — e de anormalidades — do inumano — são produzidos e transmitidos, na ordem social, pelo discurso de aspirações científicas — seja vindo da Psiquiatria, da Psicologia, da Medicina ou do Direito (BUTLER, 2015a).

Contudo, há que se ressalvar que nada há de exclusivamente "natural" nesse terreno, a começar pela própria construção da concepção dos sujeitos, pois "é através de processos culturais que definimos o que é - ou não - 'natural', assim, produzimos e transformamos a natureza e a biologia e, consequentemente, as tornamos históricas" (LOURO, 2000, p.10), sociais e culturais.

A partir dessa perspectiva, pode-se refletir que certos tipos de sujeitos vivenciarão e parecerão mais precários que outros, dependendo, por exemplo, se a performance ou morfologia corporal, apoiam ou endossam a ideia de vida humana digna de proteção, amparo, subsistência (BUTLER, 2015a) e de reconhecimento estabelecido pela ordem discursiva hegemônica. Isto é, "o enquadramento normativo estabelece de antemão que vida será digna de ser vivida, que vida será digna de ser preservada e que vida será digna de humanidade" (BUTLER, 2015a, p.15).

Assim, usando exemplo proposto por Escrivão Filho e Sousa Júnior, (p. 20, 2016) "as mulheres, as crianças (aquelas que são 'trombadinhas', 'meninos de rua', 'pivetes', 'flanelinhas', 'de menor'), o povo negro, os quilombolas, o sem-teto, os praticantes de religião ou cultos de matriz africanas" dentre tantos outros sujeitos estigmatizados e rotulados em nossa ordem social não estão dentro do qualitativo humano pois, suas vidas não se enquadram na condição de sujeitos de humanidade estabelecido pela norma hegemônica e, portanto, sequer são reconhecidos como vidas passíveis de dignidade.

O discurso de vidas passíveis de reconhecimento de humanidade e de direitos situa a concepção da condição humana como definida e regenerada aos modos de conhecimento e de poder estabelecidos na matriz cultural, assim, a precariedade, a abjeção, a vulnerabilidade social e a subalternização das vidas são orientadas pelo discurso que impõe, marca e qualifica o humano do inumano.

A noção de ser humano está condicionada ao escopo e ao significado da condição de ser reconhecido. Trata-se, pois, de compreender como "as normas para a condição do reconhecimento operam para tornar certos sujeitos pessoas reconhecíveis e tornar outros decididamente mais difíceis de reconhecer" (BUTLER, p. 20, 2015a).

Parece, então, que para que se possa ampliar as discussões quanto as reivindicações sociais, políticas e de reconhecimentos dos direitos humanos aos sujeitos, faz-se, fundamental, compreender que o horizonte normativo o qual determina o "outro" é estabelecido através de um "conjunto de normas que governam a reconhecibilidade da humanidade" (BUTLER, 2015b, p. 39). Portanto, o "outro" terá o reconhecimento da condição humana e, assim, será considerado um sujeito digno de Direitos Humanos se estiver enquadrado nas 
normas hegemônicas da condição humana.

É talvez a partir do rosto do outro que se possa encontrar um “outro" humanismo (LEVINAS, 2003). $\mathrm{O}$ "homem" precisa da superação do egoísmo. O "homem" não pode ficar indiferente à nudez e à miséria presente no rosto do outro. Antes pelo contrário, é a proximidade com o outro que faz dos humanos, mais humanos. $\mathrm{O}$ "eu" necessita do "outro". Por mais paradoxal que possa parecer, o "eu" perece ao ver a morte do "outro", embora ele muitas vezes queira o seu perecer. A relação entre os seres que não se anulam mutuamente é possível porque o outro é expresso, que se manifesta no discurso e, assim, desfaz a forma como ele oferece e que petrifica o outro. (LEVINAS, 2003).

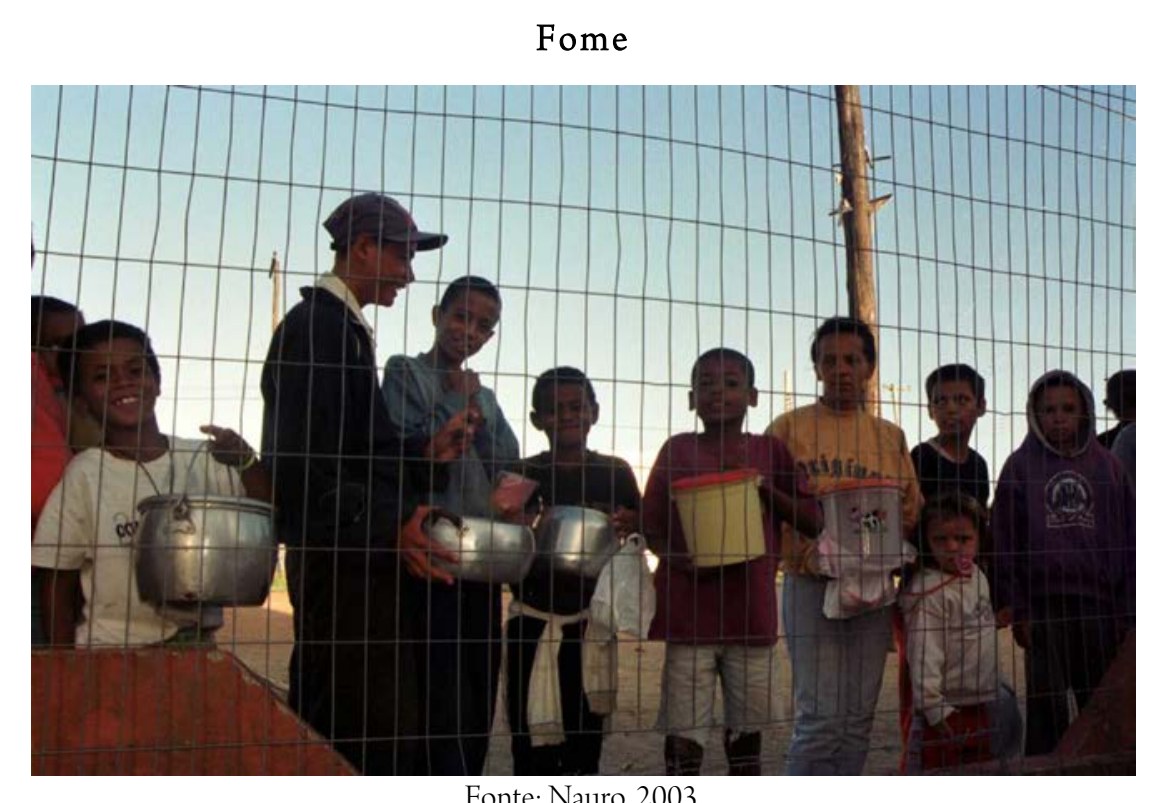

Fonte: Nauro, 2003.

Talvez seja o questionamento da condição humana um aporte importante para não somente interrogar o paradigma atual do conhecimento, mas, em especial avançar na compreensão sobre a concepção do discurso dos Direitos Humanos. Pois ao ser interrogado o consenso da condição humana, estar-se-á direcionando um olhar humanizando a estes questionamentos e, fundamentalmente, contribuindo para a construção de uma concepção da ciência jurídica, por meio da (re)significação do discurso dos Direitos Humanos, menos racista, sexista e heteronormativa ${ }^{9}$ e muito mais humanista.

\footnotetext{
${ }^{9}$ Cabe ressaltar qual o conceito de heteronormatividade é compreendido neste estudo de acordo com o proposto por Pelúcio (2009, p. 30), assim, "a heteronormatividade não é apenas uma norma hetero que regula e descreve um tipo de orientação sexual, trata-se, sim, de um conjunto de instituições, estruturas de compreensão e orientações práticas que fazem não só com que a heterossexualidade pareça coerente (organizada como sexualidade) como também que seja privilegiada". Ainda segundo a autora, esses privilégios podem ser percebidos nos discursos, como o jurídico, que, mesmo ao estabelecer hierarquias que não se pautam explicitamente pelas sexualidades ou na heterossexualidade, regulam as relações sociais a partir do pressuposto da heterossexualidade como um estado natural e moralmente desejado (PELÚCIO, 2009).
} 


\section{PLURALIZANDO A CONCEPÇÃO DOS DIREITOS HUMANOS}

Frutos de um longo processo histórico-social de agregação de valores percebidos e conquistados na luta como fundamentais à condição humana (KROHLING, 2009, p. 44) os Direitos Humanos aspiram, atualmente, uma (re)significação discursiva para que possam ser, a partir disso, considerados como um dos pilares fundamentais de uma emergente política pós-moderna.

O processo de lutas sociais pela afirmação e, sobretudo pelo reconhecimento de direitos ligados a condição humana constitui uma verdadeira conquista da sociedade moderna (WOLKMER, 2012). Esse processo de reconhecimento dos direitos ligados a condição humana, ainda que tenha sido orientando, inicialmente, "pelas ideias da cultura liberal-burguesa e pela doutrina do jusracionalismo deve-se, atualmente, à estreita conexão com as transformações sociais" (WOLKMER, 2012, p. 18), contudo, o discurso dos Direitos Humanos foi apanhado por aquela concepção e, ainda, não se recuperara dela (SANTOS, 2006).

De acordo com Santos o discurso acerca dos Direitos Humanos assentou-se "num bem conhecido conjunto de pressupostos, todos tipicamente ocidental, assim, primeiramente, concebeu-se a existência de uma natureza humana pretensamente universal que pode ser conhecida racionalmente" (SANTOS, 2006, p. 443). Entretanto, "a natureza humana é essencialmente diferente e superior à restante realidade" (SANTOS, 2006, p. 443).

Dessa forma, o que, em um primeiro momento, demonstrou-se importante na conquista e, sobretudo no reconhecimento de direitos, passou a ser repensado e questionado. Assim, o que até então era compreendido como uma reivindicação de caráter universal e uma condição absoluta demonstrou-se uma compreensão incompleta e exclusivista do contexto social (SANTOS, 2006).

Ocorre que, o discurso dos "direitos humanos universais ocidentais tornou-se a compreensão dos Direitos Humanos” (SANTOS, 2006, p. 463). A partir daí, tal construção discursiva acerca dos Direitos Humanos ocidental "se estabeleceu ao longo do tempo sob o manto da universalidade epistêmica" (SPAREMBERGER, 2015a, p.2).

Desenvolveu-se, assim, uma relação totalizadora entre os sujeitos detentores de uma pretensa racionalidade universal e, por isso, qualificados a dizer verdades sobre todos os povos do planeta, e os silenciados (SPAREMBERGER, 2015a), isto é, "acreditou-se que aqueles estavam acima das relações históricas e políticas e, deste modo, foram produzindo os discursos verdadeiros" (SPAREMBERGER, 2015a, p.2) sobre Direitos Humanos, já que pretensamente representariam o melhor para toda a humanidade.

A pretensa universalidade do discurso dos Direitos Humanos se demonstrou, todavia, uma compreensão parcial do que seriam tais direitos, já que foram construídos e significados exclusivamente a partir de uma visão ocidental hegemônica (SANTOS, 2006). O discurso dos Direitos Humanos pretensamente universal 
e emancipatórios foram, dessa forma, dominando e vitimando as culturas mais vulneráveis e subalternizando todo e qualquer saber não enquadrado no modelo universal (SPAREMBERGER, 2015b).

A partir disso - compreendendo que a imposição do discurso dos Direitos Humanos universalista justificou-se na medida que este supostamente constituiu a melhor forma que a vida humana já alcançou (ESCRIVÃO FILHO, SOUSA JÚNIOR, 2016) -, demonstra-se necessário refletir que a noção de universalidade carrega não apenas uma noção ideológica de superioridade, mas, em especial um processo histórico de imposição cultural, político e econômico (ESCRIVÃO FILHO, SOUSAJÚNIOR, 2016).

É, então, certo que o discurso de emancipação dos Direitos Humanos foi historicamente concebido para vigorar apenas de forma hegemônica, todavia, a compreensão, como já mencionado, de mundo transpõe a compreensão ocidental de mundo (SANTOS, 2010).

Sendo assim, o discurso dos Direitos Humanos desenvolveu-se através de um modelo insatisfatório por sua, via de regra, não adequação às particularidades das realidades sociais e culturais. Neste mesmo sentido, Escrivão Filho e Sousa Júnior (p. 32, 2016) utilizando-se da concepção de Santos identificam que a concepção do universal "é aquilo que se quer afirmar como válido independente dos contextos, em todos os tempos e lugares".

Dessa maneira:

muitos discursos ocidentais (científicos, jurídicos, políticos) são considerados como "universais" e, com isso, são impostos para todo planeta, diferentes dos saberes "outros" (indígenas, orientais e africanos) que são tratados como saberes menores, locais, incompletos, míticos, ou seja, inferiores (SPAREMBERGER, 2015a, p. 5).

A epistemologia ocidental que permitiu, então, o desenvolvimento da modernidade se sustentou e se impõe por meio do imaginário da existência de verdades universais e fez isso principalmente ao anular a relação do sujeito com os demais processos de conhecimento (SPAREMBERGER, 2015a). Na percepção de Santos:

nos dias atuais, há um paradigma hegemônico que impõe a realidade social um monopólio da construção do conhecimento, estruturado no pensamento visível estabelecido "deste lado da linha" e que não dialoga com "outro lado da linha" (SANTOS, 2010, p.3 8).

Desse modo, cabe mencionar que a compreensão hegemônica de direitos reconhecidos e efetivados, assim como da validade universal em meio a sistemas jurídicos inseridos em contextos políticos, econômicos, sociais e culturais (ESCRIVÃO FILHO, SOUSA JÚNIOR, 2016) deve ser questionada por meio da problematização do consenso da concepção da condição da vida humana e do cenário social e cultural, a fim de compreender o que se situa, através da ordem discursiva, como normalizado na ordem social.

Nesse contexto, Santos aponta para necessidade da realização de uma prática contra-hegemônica do discurso dos Direitos Humanos, pois "os direitos dos cidadãos não estarão seguros enquanto os não-cidadãos sofrerem um tratamento sub-humano" (p. 38, 2010). Para ele, tal prática:

além de ver nos direitos humanos uma arma de luta contra a opressão independente de condições geoestratégicas, avançam propostas de concepções não ocidentais e de direitos humanos e organizam diálogos interculturais sobre direitos humanos e outros princípios de 
dignidade humana. (SANTOS, 2010, p. 445).

Assim, a prática contra-hegemônica dos Direitos Humanos deve ser alicerçada na práxis dos movimentos sociais, bem como no trabalho teórico, estabelecido através dos questionamentos das construções teóricas que propõe a concepção do conceito de dignidade humana, de justiça social e do próprio discurso de Direitos Humanos de forma universal, generalista e individualista (SANTOS, 2010).

Frente a isso, tendo em vista os processos de dominação, interdição e subalternização com que a sociedade ainda se estrutura, os sujeitos que transpõe a ordem epistemológica, dentre eles estão as mulheres, os homossexuais, os transexuais, dentre outros, vêm apontando valores culturais diferenciados aos horizontes institucionais e, com isso, possibilitando a projeção da força dos sujeitos sociais como fonte de legitimação da constituição de direitos que se pautam pelo reconhecimento de direitos e, em especial da humanidade aos sujeitos.

\section{POR UMA EDUCAÇÃO EM E PARA OS DIREITOS HUMANOS}

Nesta perspectiva emancipatória encontra-se a potência expressa no campo da educação em e para os Direitos Humanos. Lócus privilegiado para a produção de novos mecanismos teóricos, epistêmicos e metodológicos que configurem os saberes, fazeres e discursos enquanto sujeitos em transformação.

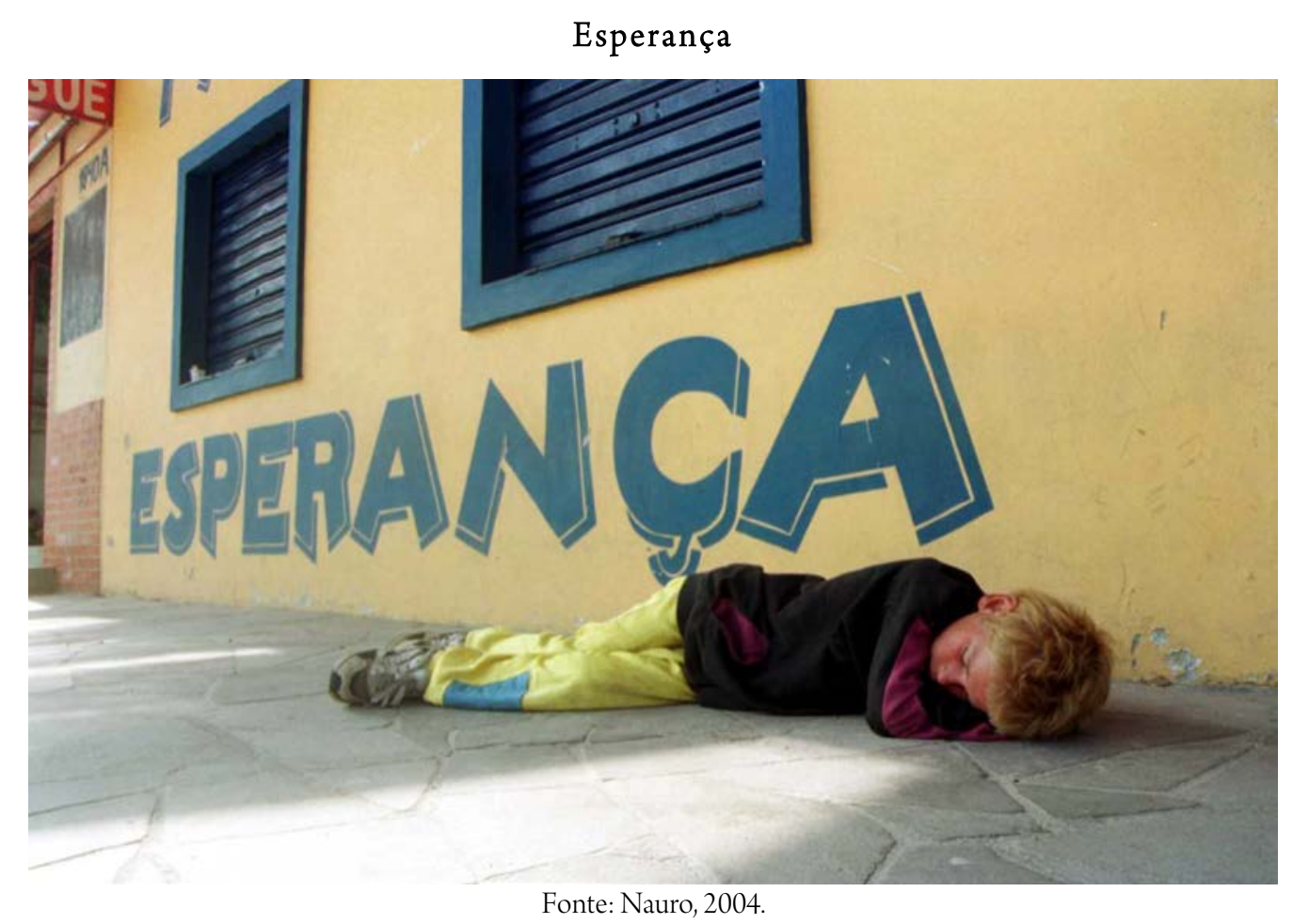

Daí se verifica, no cenário social brasileiro, a necessidade do reconhecimento da (re)significação da 
concepção da construção discursiva acerca dos Direitos Humanos; esta que possa viabilizar uma nova legitimação de saberes e, consequentemente das formas hegemônicas, pois:

não se trata de liberar a verdade de todo sistema de poder - o que seria quimérico à medida que a própria verdade é poder -, mas de desvincular o poder da verdade das formas de hegemonia (sociais, econômicas, culturais) no interior das quais ela funciona no momento (FOUCAULT, 2014, p. 54).

Diante disso, torna-se fundamental desestabilizar a compreensão tradicional da construção discursiva dos Direitos Humanos e compreendê-la por meio de uma ótica plural, pois tal olhar acerca desses direitos pode não somente ser um potente mecanismo para que o imperativo discursivo possa ser desestabilizado, como, em especial, poderá possibilitar a afirmação desses direitos de maneira contextualizada, relativa, solidária e, efetivamente, emancipatória (WOLKMER, 2012).

Este caminho se constrói a partir de uma dialética em que a educação em Direitos Humanos protagonize aloés e práticas solidárias que revertam a subalternidade, emancipando e dando voz às vidas precarizadas.

O papel da escola, o papel dos "ensinantes de cultura" (não seria tal expressão um pleonasmo?) é dar a cada um a possibilidade de compreender, como uma polifonia cristalina, as múltiplas vozes que se ouvem, de tempos em tempos, nos mais diferentes cantos do mundo. (FORQUIN, 2000, p. 67)

No campo das políticas educativas houve avanços e retrocessos. Os dois últimos Planos Nacionais de Educação (2001 e 2014) e o PNEDH - Plano Nacional de Educação em Direitos Humanos de 2006, que visa incentivar as formas de acesso às ações de educação em direitos humanos e o Decreto 7.611/2011, que dispõe sobre a educação especial, os atendimentos educacionais especializados são bons exemplos destas políticas afirmativas que pareciam demonstrar a necessidade de uma educação afirmativa. Para explicitar alguns destes documentos legais:

1. No PNE - Plano Nacional de Educação de 2001 - Modalidades de ensino e educação em direitos humanos eram metas menos especificas;

2. No PNE de 2014 a ênfase está nos seguintes artigos e metas:

Art. $2^{\circ}$ São diretrizes do PNE: [...]

II - universalização do atendimento escolar;

III - superação das desigualdades educacionais;

$[\ldots]$

VII - promoção humanística, científica e tecnológica do País;

$[\ldots]$

$\mathrm{X}$ - difusão dos princípios da equidade, do respeito à diversidade e a gestão democrática da educação

Por assim dizer, o PNE acabou por sustentar a importância da educação humanística e com respeito à diversidade, o que de fato já vinha sendo expresso em outros documentos como o PNEDH - Plano Nacional de Educação em Direitos Humanos, 2006.

A educação em direitos humanos é compreendida como um processo sistemático e multidimensional que orienta a formação do sujeito de direitos, articulando as seguintes 
dimensões: a) apreensão de conhecimentos historicamente construídos sobre direitos humanos e a sua relação com os contextos internacional, nacional e local; b) afirmação de valores, atitudes e práticas sociais que expressem a cultura dos direitos humanos em todos os espaços da sociedade; c) formação de uma consciência cidadã capaz de se fazer presente nos níveis cognitivo, social, ético e político; d) desenvolvimento de processos metodológicos participativos e de construção coletiva, utilizando linguagens e materiais didáticos contextualizados; e) fortalecimento de práticas individuais e sociais que gerem ações e instrumentos em favor da promoção, da proteção e da defesa dos direitos humanos, bem como da reparação das violações. (PNEDH, 2006)

No entanto, as temáticas de gêneros e sexualidades acabaram por ser retiradas do último Plano Nacional de Educação. O que demonstrou uma notável fragilidade destas conquistas, e, sobretudo, de nossa jovem democracia.

A retirada dos planos de educação da obrigatoriedade de inserção das discussões acerca de gênero e de sexualidades em todos os níveis educacionais proporciona que se perpetue a invisibilidade das violências praticadas em razão de atos de homofobia e de misoginia, construídos a partir de uma cultura androcentrista e heteronormativa. Através das pesquisas a que se propôs o presente trabalho, foi possível problematizar o papel da escola na produção e na reprodução destas práticas. A escola historicamente produziu e reproduziu diferenças, distinções e desigualdades, normatizando sujeitos dentro de um padrão heteronormativo constituído dentro e uma oposição binária dos gêneros, que somente constitui como normal os corpos que se constituem dentro desse padrão (feminino/masculino), colocando todos os demais, ou seja, aqueles que não se enquadram dentro deste padrão em uma zona chamada de abjeção, separando os corpos humanos, ditos naturais, dos desumanos, não naturais. (DIAS, DOMBKOWITSCH, 2015, p. 290)

Embora este retrocesso, as universidades públicas têm experimentado surpreendentes processos de mudança, especialmente no que diz respeito às políticas de inclusão. ${ }^{10}$ Dentre essas está, por exemplo, o reconhecimento, por algumas instituições federais, do uso do nome social pelas pessoas trans. ${ }^{11}$

Estes marcos locais, que potencializam sobremaneira a educação em Direitos Humanos, devem ser tomados como possíveis pistas e desvelamentos de novos caminhos que podem direcionar os discursos dos Direitos Humanos a galgarem outro patamar.

Está muito claro que o desafio contra-hegemônico se dá pela superação do paradigma dominante que silencia, sufoca e invisibiliza os corpos e vidas precárias, atuando sobremaneira na negação dos mais basilares direitos civis e humanos. Na esfera das políticas públicas, o campo da educação é solo fértil seja para reproduzir este silêncio ou romper com a mordaça da barbárie. A ruptura epistêmica pode ser, portanto, promovida por meio de uma práxis e uma educação em e para os Direitos Humanos libertadora, ativa, dialógica e transformadora.

Defende-se que o campo das teorias e das políticas educacionais pode auxiliar na compreensão dos

\footnotetext{
${ }^{10}$ Desde 2012 a Universidade Federal do Rio Grande - FURG, por exemplo, permite o acesso através de editais específicos para indígenas e quilombolas. Além destes processos seletivos especiais, as políticas e ações afirmativas têm possibilitado por meio do SISU dar possibilidade de ingresso a milhares de estudantes provenientes de escolas das redes públicas. Atualmente, a FURG, conta com um Programa de Ações Afirmativas (PROAF) que é o indutor de políticas de inclusão na universidade. Fonte: www.furg.br <acesso em 28.07.2016>.
} 
processos de transformação pelo qual tem passado a universidade e a escola (BERNSTEIN, 1996, 1998), já que, desde muito tempo, o campo dos estudos sobre políticas educativas tem possibilitando investigar os embates e as lutas, em que proliferam discussões sobre poder, controle, identidade, cultura, globalização e outras de cunho epistemológico e ontológico. Entende-se, também, que as políticas são marcadas pela heterogeneidade, conflito e ambivalência. E, sendo assim, as análises macro poderão sempre nos ser úteis para compreender os contextos locais, inclusive os existentes nas intrincadas relações produzidas pelos textos legais e os contextos de sala de aula.

Nesse sentido, direito e educação se entrelaçam para compreensão destas arenas de conflito podendo potencializar, assim, uma razoável compreensão de como o macro e o micro se articulam (BERNSTEIN, 1996) na operacionalização do currículo e da estrutura organizacional do conhecimento, principalmente em termos de políticas públicas educativas.

Baseado nesses argumentos pensa-se fundamental articular um conceito de justiça social na perspectiva crítica. Santos (2006) advoga esta concepção de justiça, explorando os dois aspectos fundantes: a igualdade e a diferença. $\mathrm{O}$ conceito de justiça está, portanto, vinculado ao equilíbrio de dois atributos: diferença e igualdade, já que "temos o direito a ser iguais sempre que a diferença nos inferioriza; temos o direito de ser diferentes sempre que a igualdade nos descaracteriza" (SANTOS, 2006, p. 316).

\section{CONSIDERAÇÕES FINAIS}

A concepção do discurso dos Direitos Humanos vem sofrendo, atualmente, diversos questionamentos e várias interrogações, frente a essa realidade, este estudo, buscou problematizar e refletir acerca da construção discursiva desses direitos.

Ocorre que, como a matriz discursiva opera no sentido de (re)afirmar e (re)produzir as fronteiras entre o verdadeiro; o humano; o normal e o falso; o inumano; o anormal, demonstra-se fundamental, questionar as construções discursivas que propõe a concepção do conceito de humanidade e do próprio discurso de Direitos Humanos de forma universal, generalista e individualista.

Diante disso, torna-se fundamental interrogar quais vidas são enquadradas como humanas e, portanto, sujeitas à humanidade e passíveis de Direitos Humanos, pois, em no contexto social e cultural atual, demonstra-se urgente transgredir a violência normativa do conceito de humanidade.

Ainda, frente à capacidade epistemológica de precarizar e subalternizar determinados sujeitos e, portanto, vidas mostra-se, também, necessário refletir e questionar a noção de universalidade estabelecido pela construção discursiva dos Direitos Humanos. Impõe-se, neste contexto, evidenciar a necessidade do reconhecimento da

\footnotetext{
${ }^{11}$ A Universidade Federal do Rio Grande de forma vanguardista já em 2013 possibilitou a seus discentes a utilização do nome
} vol.10, no. 04, Rio de Janeiro, 2017.pp. 2396-2412 
(re)significação da concepção da construção discursiva acerca dos Direitos Humanos; esta que possa viabilizar uma nova legitimação de saberes e, consequentemente das formas hegemônicas.

Assim, ao abordar a necessidade da (re)significação da concepção do discurso de Direitos Humanos, esta pesquisa, pretendeu, portanto, problematizar a necessária oposição à episteme atual do conhecimento, pois ao ser questionada a ordem epistemológica, estar-se-á dando passos importantes para a constituição dos Direitos Humanos contextualizados, relativos, solidários e efetivamente emancipatórios.

A educação em e para os Direitos Humanos pode potencializar a produção de um conhecimento emancipado; pode dar voz a quem foi silenciado; pode reconfigurar corpos e vidas precárias. Na argumentação de Butler, a representação da alteridade constitui-se em um meio de humanização/des-humanização, de reconhecimento do vínculo ético-moral com o "outro" ou de justificativa para sua eliminação.

É preciso, por fim, como aponta Butler, olhar para a questão da precariedade articulada com a desigualdade econômica e privação política que hierarquiza corpos, criando grupos de pessoas "merecedoras" de direitos e outras, com diz "designadas como dispensáveis e indignas de luto”.

\title{
REDEFINING THE DISCOURSE OF HUMAN RIGHTS: A DIALOGUE FROM THE EDUCATION IN AND FOR HUMAN RIGHTS
}

\begin{abstract}
This study aims at reflecting on the modern conception of the discourse of Human Rights. For this purpose, we performed a literature review from the research technique of indirect documentation, with a narrative nature, based on cultural and postmodern studies of critical matrix. Firstly, we ask about which lives are considered human and, consequently, subjected to humanity and prone to Human Rights. In a second moment, we made a reflection on the discursive redefinition of these rights. Thus, we intend to emphasize the necessary opposition to the traditional episteme of knowledge, especially regarding the discourse of Human Rights, since the regime of truths, by reaffirming the production of skills through power relations, allows it to make a hegemonic discursive construction, as well as restrains its knowledge in relation to the current discursive policy. In this approach, we understand that the education in and for Human Rights is a powerful space for changing these contexts, since it can not only optimize the production of an emancipated knowledge and give voice to those who have been silenced, but, especially, can reconfigure precarious bodies and lives.
\end{abstract}

Keywords: Human Rights; Recognition; Human Condition; Hegemonic discourse; Human Rights education.

social. Fonte: www.furg.br <acesso em 28.01.2017>. 


\section{REFERENCIAS}

BERTÚLIO, Dora Lucia de Lima. O "novo" direito velho: Racismo e Direito. In.: Diversidade sexual, relações de gênero e politicas públicas. (ORG): NARDI, Henrique Caetano SILVEIRA, Raquel Silva, MACHADO, Paula Sandrine; Porto Alegre: Ed. Sulinas, 2013.

BERNSTEIN, Basil. A estruturação do discurso pedagógico: classe, códigos e controle. Petrópolis, RJ: Vozes, 1996.

Pedagogía, Control Simbólico e Identidad. Madrid, Espanã: Ediciones Morata, 1998.

BRUM, Amanda. Netto, DIAS, Renato. Duro. O (re)conhecimento trans. In.: Sociologia, antropologia e cultura jurídicas. [Recurso eletrônico on-line]. (ORG): CONPEDI/UFS. 1ed. Aracaju, Brasil: Editora CONPEDI/UFS, 2015, p. 1-15.

BUNCHAFT, Maria Eugenia. Transexualidade no STJ: Desafios para a Despatologização à luz do debate ButlerFraser. Disponível em:

http://www.academia.edu/25353784/Transexualidade_no_STJ_desafios_para_a_despatologiza\%C3\%A7\% C3\%A3o_\%C3\%A0_luz_do_debate_Butler-Fraser $>$. Acesso em 01 de ago. 2016.

BUTLER, Judith. Cuerpos que importan. Sobre los limites materiaes y discursivos del "sexo". Bs As. (Argentina). Paidós, 2012.

Quadro de guerra: Quando a vida é passível de luto? Rio de Janeiro: Civilização Brasileira, 2015a.

Judith Butler: Relatar a si mesmo: crítica da violência ética. 1 ed. Tradução: BETTONI, Rogério. Belo Horizonte: Autêntica Editora, 2015b.

COURTINE. Jean-Jacques. Decifrar o corpo: Pensar com Foucault. Petrópolis, RJ: Editora Vozes, 2013.

DETONI, Patrícia Pavan, GOULART, Lucas Aguiar. A Mulher-Mãe e o Homem-Ausente: notas sobre feminilidades e masculinidades nos documentos das políticas de assistência social. In.: Diversidade sexual, relações de gênero e políticas públicas. (Org): NARDI, Henrique Caetano, SILVEIRA, Raquel Silva, MACHADO, Paula Sandrine. Porto Alegre - RS/Brasil: Ed. Sulinas, 2013.

DIAS, Renato Duro. Interdição de gênero: a lei que silencia o corpo. In.: Direito, arte e literatura. (ORG): CONPEDI/UFMG/FUMEC/ Dom Helder Câmara. [Recurso eletrônico on-line]. 1 ed. Belo Horizonte: CONPEDI 2015, 2015.

Relações de poder e controle no currículo do curso de direito. Rio de Janeiro: Lumen Juris (no prelo).

DIAS, Renato Duro e DOMBKVICH, Luciana. Direito humano à educação: a inclusão das temáticas de gênero e de sexualidades nos planos de educação. In: Direito, educação, epistemologias, metodologias do conhecimento e pesquisa jurídica II. [Recurso eletrônico on-line]. (ORG): CONPEDI/UFMG/FUMEC/Dom Helder Câmara- Florianópolis: CONPEDI, 2015.

DIAS, Renato Duro, ALVES, Ricardo Henrique Ayres. A imagem do corpo masculino erotizado como potência reflexiva no campo religioso. 2012. Disponível em: <http://www.snh2013.anpuh.org/resources/anais/27/1371351461 >. Acesso em 29 de dez. de 2013.

ESCRIVÃO FILHO, Antônio, SOUSA JUNIOR, José Geraldo de. Para um debate teórico-conceitual e político sobre os DIREITOS HUMANOS. Belo Horizonte: Editora D’Plácido, 2016. 
FORQUIN, Jean-Claude. O currículo entre o relativismo e o universalismo. Educação \& Sociedade, ano XXI, nº 73, Dezembro/00.

FOUCAULT, Michel. A história da sexualidade vol. 1 - A vontade de saber. Rio de Janeiro: Graal, 2010. Microfísica do Poder. 28 ed. Rio de Janeiro: Paz e Terra, 2014.

KROHLING, Aloísio. Direitos humanos fundamentais - Diálogos Interculturais e Democracia. São Paulo: Editora Paulus, 2009.

LEVINAS, Emannuel. Humanismo del otro hombre. México: Siglo XXI, 2003.

LOURO, Guacira Lopes. O corpo educado: pedagogias da sexualidade. Belo Horizonte, brasil. Editora Autêntica, 2000.

PELÚCIO, Larissa. Abjeção e desejo: uma etnografia travesti sobre o modelo preventivo de aids. São Paulo, Brasil: Editora Annablume: Fapesp, 2009.

SANTOS, Boaventura de Sousa. A gramática do tempo: para uma nova cultura política. São Paulo: Cortez, 2006.

Para além do pensamento abissal: das linhas globais a uma ecologia dos saberes. In.: SANTOS, Boaventura de Sousa, MENESES, Maria Paula. Epistemologia do Sul. São Paulo: Cortez, 2010.

SPAREMBERGER, Raquel Fabiana Lopes. Ressignificação dos marcos teóricos e epistêmicos do constitucionalismo moderno/colonial: Um olhar para os sujeitos e saberes tradicionalmente subalternizados, 2015a. Disponível em: <http://www.fmp.edu.br/institucional/346/ressignificacao-dos-marcos-teoricos-eepistemicos-do-constitucionalismo-moderno-colonial/>. Acesso em 10 de dez. de $2015 a$ a. p. 1-22.

O conhecimento jurídico colonial e o subalterno silenciado: Um olhar para o pluralismo jurídico. In.: Constitucionalismo, descolonización y pluralismo jurídico en América Latina. (Org): Wolkmer, Antônio Carlos; Lixa, Ivone Fernandes M./Aguascalientes: CENEJUS / Florianópolis: UFSC-NEPE, 2015b.

TONELI, Maria Juracy Figueiras, AMARAL, Marília dos Santos. Sobre travestilidades e Políticas Públicas: Como se produzem os sujeitos da vulnerabilidade. In.: Diversidade sexual, relações de gênero e políticas públicas. (ORG): NARDI, Henrique Caetano SILVEIRA, Raquel Silva, MACHADO, Paula Sandrine; Porto Alegre: Ed. Sulinas, 2013.

WOLKMER, Antônio Carlos. Introdução aos Fundamentos de uma Teoria Geral dos "Novos" Direitos. In.: Os "novos direitos no Brasil-Natureza e Perspectivas - Uma Visão Básica das Novas Conflituosidades Jurídicas". (Org): WOLKMER, Antônio Carlos, MORATO LEITE, José Rubens. 2 ed. São Paulo: Saraiva, 2012.

Trabalho enviado em 21 de setembro de 2016.

Aceito em 05 de março de 2017. 